\title{
Framing the Future: Embryonic Stem Cells, Ethics and the Emerging Era of Developmental Biology
}

\author{
WILLIAM B. HURLBUT \\ Department of Neurology and Neurological Sciences [W.B.H.], Stanford University Medical Center, Stanford, CA 94305
}

\begin{abstract}
Throughout the $20^{\text {th }}$ century, advances in biology were accomplished largely through the study of biochemical parts apart from their place within the whole organism. This reductive and analytic approach, which has culminated in the sequencing of the human genome, has now led us back to the study of living beings. When applied to human biology, this inquiry re-opens the most fundamental questions concerning the moral meaning of developing life. The current conflict over ES (embryonic stem) cell research is just the first in a series of difficult controversies that will require us to clearly and precisely define the boundaries of humanity that we seek to defend. Through a careful consideration of the social, political, and scientific foundations of our current debate, we may discern the terms of a possible resolution that can sustain social consensus while opening avenues for scientific advance. Four such proposals were discussed in a May 2005 publication by the President's Council on Bioethics, entitled "Alternative Sources of Pluripotent Stem Cells." One of these methods, altered nuclear transfer, proposes to use the technology of somatic cell nuclear transfer (SCNT), but with a pre-emptive genetic or epigenetic alteration that precludes the integrated and coordinated organization essential for natural embryogenesis. The moral and scientific dimensions of this proposal are discussed as a way forward for embryonic stem cell research as well as a frame for further studies in developmental biology. (Pediatr Res 59: 4R-12R, 2006)
\end{abstract}

$I^{n}$ n 1779, the French Academy of Science offered a prize of one kilo of gold to anyone who could explain the nature of alcohol fermentation. For 6000 y, fermentation had been regarded as a mysterious power of transformation, a meeting of the material and the spiritual. But now, in the age of science, a bitter dispute arose between those representing the new field of chemistry and the traditional "vitalists," who maintained that life processes are not reducible to explanations in terms of physio-chemical mechanism (1).

Toward the end of the $18^{\text {th }}$ century, Lavoisier had noted that the powers of fermentation could be transferred with residual sediments. By the middle of the $19^{\text {th }}$ century, Schwann established that cells are the basic unit of life, and that yeast cells could be found in fermentation sediments. The crucial role of these yeast cells was confirmed by Pasteur, who maintained that only within the living system of the cell, with its mysterious, immaterial vital forces, could the powers of fermenta-

Received December 13, 2005; accepted December 14, 2005.

Correspondence: William B. Hurlbut, M.D., Stanford University Medical Center, Department of Neurology and Neurological Sciences, 371 Serra Mall, Room 345, Gilbert Hall, Stanford, CA 94305-5020; e-mail: ethics@stanford.edu

DOI: $10.1203 / 01 . p d r .0000205377 .04359 .3 e$ tion be manifest. But in 1897, the German chemist Eduard Büchner prepared an extract of yeast and noted that this clear, slightly yellow, filtered fluid was fully capable of fermentation even apart from its cellular source.

Büchner's discovery led to the isolation of the enzymes of fermentation and the chemical description of this fundamental organic process. With this decisive blow to vitalism, the field of biochemistry was born and with it the reductive and analytic approach to the study of life.

The practical significance of this conceptual revision is evident in the dramatic advances in biology throughout the $20^{\text {th }}$ century. By breaking down organic systems into their component parts and looking at living beings in terms of inanimate matter, we opened an era of scientific discovery that has culminated in the sequencing of the human genome. Now, however, as we move from genomics to proteomics and on to the investigation of developmental biology, we are returning to the study of whole living beings. When applied to human biology, this inquiry reopens the most fundamental questions concerning the very definition of life and the adequacy of our current scientific approach to inform discussion of the ethical dilemmas raised by our new perspectives and powers.

These questions have been forced to the foreground of public awareness by our deepening controversy over embryonic stem cell (ESC) research, and most specifically by proposals for the production of cloned human embryos as a source of these cells. This conflict is sometimes framed as a battle between the subjectivity of personal religious belief and the objectivity of science, but it is far more fundamental than that. Distilled in this difficult debate are the most profound considerations concerning the relationship between the material, physiochemical mechanisms and the moral meaning of human life.

A careful consideration of the foundations of this controversy can place it within a broader social and scientific context and bring into focus the crucial concerns that underlie our present political impasse. Drawing on this debate, particularly as it developed within the President's Council on Bioethics (on which I serve), we can discuss the immediate ethical issues in ESC research. At the same time, we can seek a wider
Abbreviations: ANT, altered nuclear transfer; CBR, cloning for biomedical research; ESC, embryonic stem cell; HHS, Health and Human Services; IVF, in vitro fertilization; NIH, National Institutes of Health 
understanding that may set the frame for scientific and medical advance in the era of developmental biology. It is clear that ESC research is just the first of many dilemmas that will challenge our traditional understanding of human life. Parthenogenesis, human-animal chimeras, human body parts grown in laboratories - these and a wide range of other emerging technologies make it imperative that we define the boundaries of humanity with clarity and precision to preserve the essential unity of the human person.

Through such a reflection on the meaning of human embodiment, we may draw a distinction between the material parts and the living whole that defines the locus of our moral concern. This distinction may suggest a way forward that will allow positive progress in biomedical science while preserving our most fundamental principles for the protection of human subjects and the defense of human dignity.

\section{SOCIAL AND POLITICAL FOUNDATIONS}

On August 9, 2001, President Bush, in his first major policy address to the nation, discussed what he described as "a complex and difficult issue, an issue that is one of the most profound of our time," the scientific and moral considerations in stem cell research.* He described the wide consultation and deep reflection that had gone into his consideration of the important yet competing goods at stake. And he announced that after several months of difficult deliberation he had decided that federal funds would be made available to support research with certain already extant ESC lines, but would not support research that would encourage any further destruction of human embryos. Some regarded this decision as a cynical political compromise while others saw it as a courageous acknowledgement of the important values on both sides on this difficult debate. Few, however, seemed to have understood either the historical foundations or the legal constraints within which this policy decision was made.

The issue of research on embryos and fetuses has been the subject of controversy and conflict for more than thirty years. With the advent of in vitro fertilization (IVF) in the late 1970s, the laboratory production of large numbers of human embryos became possible, and with them opportunities to study fertilization and early embryonic development. At the same time strong objections were raised that taxpayers dollars not be put toward specific sorts of research that violates the moral convictions and sensibilities of a large portion of the American public.

Over the next decade and a half a series of national commissions and advisory boards made various recommendations but funding was effectively blocked, first by a congressional moratorium and then by a de facto ban by the Department of Health, Education and Welfare. In 1994, the National Institutes of Health (NIH) convened the Human Embryo Research Panel that made two recommendations. First, they recommended federal funding for some forms of research using embryos left over from IVF procedures. And second, they

*Remarks by the President on Stem Cell Research. Office of the Press Secretary August 9, 2001. concluded that, in some circumstances, federal funds should support the direct creation of human embryos with the explicit intention of using them for research purposes.

President Clinton overruled the panel on the latter point, but he did accept the panel's first recommendation and permitted the National Institutes of Health to consider applications for funding of research using embryos left over from IVF procedures. Congress, however, did not endorse this course of action. Toward the end of 1995, before any funding proposals had been approved by the National Institutes of Health, Congress attached language to the 1996 Departments of Labor, Health and Human Services (HHS), and Education, and Related Agencies Appropriations Act (the annual budget bill that funds the HHS and the National Institutes of Health) prohibiting the use of federal funds for any research that destroys, discards or seriously endangers human embryos, or that creates them for research purposes. This provision, known as the "Dickey Amendment" (2), has been attached to the HHS appropriations bill each year since 1996. Everything about the subsequent debate must be understood in the context of these legal restrictions.

The Dickey Amendment effectively prohibits the use of federal funds to support any research that endangers or destroys human embryos; it does not prohibit the conduct of such research using private funding. The amendment expresses the ethical conviction, as represented in the United States Congress, that nascent human life should be protected, not instrumentally used in scientific research, however promising that research may be. And, while not proscribing such research, it affirms that at the very least the destruction of human embryos should not be supported or encouraged by taxpayer dollars.

The first year after the Dickey Amendment took effect the cloning of Dolly was announced, and just two years later the isolation of human ESCs from IVF embryos was accomplished. These developments, with their promise of new avenues of progress in science and medicine, caused great excitement within and beyond the scientific community. There were new calls for federal funding of embryo research and specifically for the creation of tissue compatible sources of ESCs by "therapeutic cloning." However, most members of Congress did not change their position, and the Dickey Amendment has been re-enacted by a large majority every year since-most recently with a provision prohibiting federal funding for the creation of cloned embryos.

This seemed to close the question of the use of federal funds for human ESC research, but in 1999, the General Counsel of the HHS argued that the wording of the law might permit the use of federal funds for the study of ESCs lines if the actual destruction of the embryos from which they were obtained was done off-site and with private funds. Critics objected that such an interpretation was a technical loophole, consistent only with the letter but not the spirit of the law. President Clinton, however, accepted this approach and ordered that guidelines be drawn up for its implementation. But these guidelines were completed just before the end of the Clinton administration and were never put into practice. 
When President Bush took office in January, 2001, these new regulations were put on hold pending review and the search for a way forward that would uphold the spirit (and not just the letter) of the Dickey amendment. The hope was expressed that, while continuing to withhold taxpayer support for the destruction of human embryos, some moral good might be drawn from the existing stem cell lines, given that the destructive acts that produced these lines could not now be undone. It was with this combination of concerns and intentions (and within the constraints of existing law) that, on August 9, 2001, the President announced the approval of federal funding of research using ESC lines created before the date of his announcement, estimated to be in the range of 60-70 lines. At the same time, acknowledging the serious ethical dilemmas across a range of issues raised by rapid advances in biotechnology, the President announced the establishment of the President's Council on Bioethics.

\section{THE PRESIDENT'S COUNCIL ON BIOETHICS DELIBERATIONS ON CLONING}

President Bush set the following mandate for this Council: First, to monitor stem cell research and to recommend appropriate guidelines, and then to consider more broadly the medical and ethical ramification of biomedical innovation. Further, he asked that the Council help serve as the conscience of the country, to engage and educate the public and to advise him and the nation by articulating the strongest arguments on all sides of these difficult issues. Our initial assignment was to address the controversy over human cloning and its prospects for both reproductive and research purposes. $\dagger$

In reflecting on these dilemmas, it was immediately clear that we are at a defining moment in the progress of science. The choices our society makes now regarding ESCs (and other ethically controversial uses of biomedical technology) will put into place both the conceptual principles and practical foundations for future techniques of research and patterns of clinical practice. Once established, these moral precedents and scientific techniques will serve as the platform on which further practice will be built layer upon layer; like the foundations of a building, these will be difficult to retract or revise. There was an earnest intensity and sense of seriousness to the Council's discussion of these matters; we recognized that the issues are of broad significance for our civilization and, indeed, the future of our species. Therefore, the foundations we set must transcend pre-established cultural preferences and partisan political agendas; they must establish the basis for social consensus and global cooperation. We understood that without clear and distinct ethical principles, grounded in scientific evidence and reasoned moral argument, no policy could be effectively formulated or enforced.

The Council's discussion of the ethical issues centered around two poles, with the scientific and medical promise on the one hand, and the prudential and moral concerns on the other. Through a wide range of expert testimony and public

$\dagger$ In the account that follows I speak from the perspective of my own experience and not for the Council as a whole. comment, a compelling case was made for the importance of stem cell biology and its potential significance in medical application. The convergence of technologies following from advances in genomics, cytology, and developmental biology are delivering unprecedented powers for scientific research and intervention at the most basic levels of human biology. The fundamental questions of human embryology are opening up: studies of cell signaling, imprinting and differentiation, the positional cues that establish the body axes, body plan and patterns of organogenesis. An understanding of these basic biologic processes, together with a resource of ESCs from a full range of genotypes reflecting both normal and pathologic potentials, would provide extraordinary tools for the modeling of disease, studies of toxicology and testing of pharmaceuticals. An estimated 150,000 babies are born every year in the US with congenital defects, and evidence suggests that a range of later pathologies have their foundations in early development. Furthermore, basic developmental processes, and their disordered dynamics, seem to be at work in a number of adult pathologies including some forms of cancer. Notwithstanding the obvious hyperbole in the political promotion of ESC research ("128 million Americans with incurable diseases might benefit"), it seems clear that we truly are entering a new era of uncharted opportunity for scientific and medical advance. The age of regenerative medicine, cell therapies, tissue rejuvenation, and custom organ replacement seems conceptually real even if not within immediate reach. Far more than just ESC science is at stake; hanging in the balance are the wider scientific and medical prospects of this whole emerging era of discovery.

We recognized, however, that the same technological powers that offer such positive possibilities might also radically revise the traditional role of medicine. Clearly, increasing knowledge of reproduction and developmental biology could be used for purposes beyond therapy in the pursuit of broader human aspirations and ambitions. Disease and disability, the meaning of aging, and the significance of suffering all seemed at issue-and with them the open possibilities of human enhancement and dramatic extension of the human lifespan.

As we explored these matters, the debate deepened concerning the ultimate goals of our biomedical technology. Concerns were expressed about exaggerated expectations and images of human perfection. Some spoke of the imprudence of even entering such an arena of human enhancement and the danger in disrespecting the ordered goodness of the given world. They cited the increasing arrogance that is attending our advances in technological power as we override both the constraints of natural reality and the wisdom of traditional principles and prohibitions. And they warned that any encouragement of cloning of human embryos, for whatever immediate intentions, would provide the platform for the inevitable accomplishment of reproductive cloning. This, in turn, could set the stage for those promoting projects of "technological transcendence" through programs of eugenics and controlled evolution for the production of "posthumans" superior by design.

While pondering the scientific and medical meaning of cloning, in much of the scientific testimony and Council 
discussion there were efforts to distinguish 'therapeutic cloning' and its scientific goals from cloning with a procreative intention. However, even the question of what to call the cloning procedure and its product occupied an entire session of a Council meeting. Some argued that all human cloning is reproductive, and that when used for research, embryonic human lives are simply killed at an early stage of their development. Others claimed that the laboratory nature of the cloning procedure means that the entities produced should not be called embryos at all; "clonote" was suggested in place of the traditional term zygote. Arguments were made for "SCNTconstruct," "embryoid blastocyst" or "pseudozygote" to distance the terminology from the natural human sentiments associated with the word embryo (3). In the end, we decided that the terminology should describe the nature of the procedure, it's purpose, and the entity produced, and agreed that 'therapeutic cloning' should be called 'cloning-for-biomedical-research' (CBR) and 'reproductive cloning' should be called 'cloning-to-produce-children'.

Likewise, we explored the question of whether there was a compelling case for the importance of CBR, given the attendant moral dilemmas and social conflict, and whether other sources of cells might meet the same scientific and medical goals. Scientists at several sessions described hopeful progress in obtaining pluripotent cells (the functional equivalent of ESCs) from non-embryonic sources such as bone marrow and neural stem cells. Others explained projects to re-program or transdifferentiate adult cells as an alternative to any embryodestructive research. Nonetheless, a strong case was made for the scientific and medical value of ESCs of specific patient genotypes to study genetic disease and possibly for immune compatible cell therapies.

However, questions were raised about reports of genetic instability and epigenetic errors in cloned ESC lines, and therefore about their potential usefulness for modeling disease, drug testing, and clinical application. Some cited the difficulty of emulating the spatio-temporal dynamics and complex microenvironments of natural embryogenesis in efforts to produce the specialized cells and tissues promised for cell therapies. They pointed to ongoing research in ectogenesis, and worried out loud about the temptation to gestate human embryonic clones to later stages for the procurement of more fully and properly differentiated cells, tissues, and even organ and limb primordia. Deep concerns were expressed in both scientific testimony and public comment about the commodification and commercialization of human eggs, the patenting of laboratory generated life, and the industrial scale production of embryos for cells or cytoplasmic growth factors.

In considering the social implications of stem cell research, the hopeful prospects of lifting the burden of disease and disability weighed heavily in the Council's considerations. But some questioned the practicality of creating customized cloned embryos to provide the promised personal repair kit for every needy individual. They criticized those who sought to persuade the politics by exciting expectations of cures for diabetes or Alzheimer's disease in a generation that was unlikely to be the beneficiary of this research. Likewise, they cited matters of social justice, the enormous economic cost of personalized medicine and the inequalities in distribution that would exacerbate a medical system already badly out of balance. They suggested that given these inevitable inequities, and the controversial and speculative nature of ESC research, that there should be a comprehensive ban on all forms of human cloning, a ban that would encompass both the public and private sector.

Others Council members, however, pointed to the social obligation of laying the foundations for the future, the imperative of healing and the trickle-down effect that often follows medical advances at first available only to the rich. They maintained that the ethical objections of some should not constrain the personal liberty of others, that even if we are not going to support this hopeful research with federal funding, that our nation has a long established legal foundation for freedom of choice in matters related to medicine and reproductive rights. In a society that permits the creation of excess embryos in IVF and allows abortion up to and beyond the end of the second trimester, it seemed to them a small leap of logic to extend this principle of private choice to the laboratory creation of cloned embryos for important medical goals. Others responded that by this principle there should equally well be a constitutional right to reproductive cloning.

Disentangling these many inter-related issues and balancing the competing principles proved more difficult than anticipated, but in the end, the Council agreed there should be a legal ban on reproductive cloning. Our concern was based on more than the likely medical dangers. We felt that cloning for reproductive purposes is something that touches (and would adversely alter) fundamental aspects of our humanity: issues of identity and individuality, the relationship between the generations, and the transformation of procreation into a process of manufacture. Our vote on this was unanimous.

However, CBR was a far more difficult matter, with so much at stake and so many competing goods to weigh. Of central concern was the embryo issue. All of the other considerations, including the troubling issues related to the use of human eggs, seemed to be more matters of prudent regulation than disagreements over fundamental principle. But with regard to the moral standing of the embryo, it was apparent that deep differences in basic assumptions were precluding social consensus. Yet it was not simply personal beliefs or different cultural traditions, nor was it simply lack of scientific understanding that was dividing the debate. It seemed clear that within the current frame of discussion we lacked conceptual tools and terms of understanding adequate to bring resolution. It was as though the conceptual revolution that opened such extraordinary avenues of advance in basic biology has now delivered dilemmas where its analytic and reductive assumptions and methodologies are inadequate to address.

To resolve the conflict concerning the human embryo, we needed to find a framework to explore the most fundamental questions concerning the very source of our moral standing and the ways human life is morally different from the other life forms that we use respectfully but instrumentally for human good. We had to ponder what potential capabilities and manifestations of form or function, endow a developing life with human value and inviolability. Similarly, we had to ask what 
lack of these qualities or capacities reduces a biologic entity to raw material, mere matter and information, to be instrumentally used for projects of the human will.

Ultimately, we recognized that more time was needed for a thorough and thoughtful consideration of the moral status of the human embryo. The Council as a group acknowledged that this is not simply an issue of balancing competing goods, but that fundamental principles are at stake that are not amenable to compromise or negotiated resolution. After extended deliberation, a majority of the Council felt that the wisest course of action for our nation was a four-year moratorium on CBR.

It is in the spirit of this continuing dialogue that I offer the following ethical analysis and practical extension of its principles in the search for a solution to our difficult national debate.

\section{THE MORAL MEANING OF EMERGING LIFE}

Assessing the moral status of the embryo begins with affirming the moral status of human life in general (4). The principle that human life constitutes the fundamental good serves as the cornerstone of law for our civilization. In no circumstance is the intentional destruction of the life of an innocent individual deemed morally acceptable. This valuing of human life is indeed the moral starting point for both advocates and opponents of CBR, and it flows from the reciprocal respect that we naturally grant as we recognize in the other a being of moral equivalence to ourselves. It leads to the principle of inviolability of human life and the prohibition against using human life instrumentally.

From the perspective of those who object to research that involves destruction of embryos, an evaluation of the moral significance of human life must take into account the full procession of continuity and change that is essential for its development. From this perspective, we must consider how, from conception, our unique genetic endowment organizes and guides the expression of our particular nature in its species and individual character. With regard to fundamental organismal existence (and inviolable moral standing), the act of fertilization is a leap from zero to everything. The gametes, which are properly understood as instrumentalities, parts of the bodies of the parents, are not, in themselves, potential life; they are potential causes of conception. The gametes themselves cease to be; they do not unite in the sense of merely forming a larger composite, but bring into existence a whole new entity, a new human life.

In both character and conduct, the zygote (the one-cell embryo) and subsequent embryonic stages differ from all other cells or tissues of the body; they contain within themselves the organizing principle of the full development of a human being. This is not an abstract or hypothetical potential in the sense of mere possibility. Rather, it is a self-contained potency, an engaged and effective potential-in-process, an activated dynamic of development in the direction of human fullness of being.

Unlike an assembly of parts in which a manufactured product is in no sense present until there is a completed construction, a living being has a continuous unfolding exis- tence that is inseparable from its emerging form. The form is itself a dynamic process rather than a static structure. In biology, the whole (as the unified organismal principle of growth) precedes and produces the parts. It is this implicit whole, with its inherent potency that endows the embryo with its human character and therefore, from this perspective, its inviolable moral status. To interfere in its development is to transgress upon a life in process. The principal of this analysis will apply to any entity that has the potency of a human embryo produced by natural fertilization, regardless of whether it is the product of IVF, cloning or other processes.

\section{ACCRUED MORAL STATUS}

The major alternative to the view that an embryo has an inherent moral status is the assertion that moral status is an accrued or accumulated quality related to some physical dimension of form or function. Several arguments have been put forward for this position.

Gastrulation. One such accrual argument is based on the assumption that before gastrulation (which begins with the formation of the primitive streak around the fourteenth day), the embryo is an inchoate clump of cells with no actuated drive in the direction of distinct development. It is argued that the undifferentiated quality of the blastocyst (the 4-5 d embryo) justifies its disaggregation for the procurement of stem cells, while the evident organization at gastrulation reveals an organismal integrity that endows inviolable moral status to all subsequent stages of embryological development.

However, scientific evidence supports the opposing argument that from conception there is an unbroken continuity in the differentiation and organization of the emerging individual life. The antero-posterior axis appears to be already established within the zygote; the first cell divisions are asymmetric and early differences in gene expression suggest distinct cell fates, and an overall pattern of integrated unity seems to indicate a coherence of coordinated growth from the beginning.

All this implies that the changes at gastrulation do not represent a discontinuity of ontological significance (a change in the nature of being), but merely the visibly evident culmination of more subtle developmental processes at the cellular level that are driving in the direction of organismal maturity (5-7).

Twinning. Another argument for accrued moral status is that as long as an embryo is capable of giving rise to a twin it cannot be considered to have the moral standing of an individual. Yet monozygotic twinning, which occurs in just one in 240 births, does not appear to be either an intrinsic drive or a random process within embryogenesis. Rather, it results from a disruption of normal development by a mechanical or biochemical disturbance of fragile cell relationships. This provokes a compensatory repair, but with the restitution of integrity within two distinct trajectories of embryological development (8).

In considering the implications of twinning for individuation, one might better ask the question from the opposite perspective. What keeps each of the cells of the early embryo 
from becoming a full embryo? Clearly, crucial relational dynamics of position and intercellular communication are already at work establishing the unified pattern of the emerging individual (9). From this perspective, twinning is not evidence of the absence of an individual, but of an extraordinary power of compensatory repair that reflects more fully the potency of the individual drive to fullness of form even in the earliest stages of embryonic human life.

Implantation. Some have argued that the implantation of the embryo within the uterine lining of the mother constitutes a moment of altered moral status. Implantation, however, is actually a process that extends from around the sixth or seventh day to about the eleventh or twelfth day when the utero-placental circulation is established. The more complex circulatory exchange of the placenta simply extends the earlier relationship between mother and embryo in which diffusion of essential nutrients and growth factors sustain the life and nourish the growth of the developing embryo. Implantation, then, must be viewed as just another step in a continuum of ongoing intimate dependence, all occurring along the trajectory of natural development that begins with conception and continues into infancy. This continuity implies no meaningful moral marker at implantation.

Some argue in the case of IVF, however, that before implantation the embryo has no future prospects of development and therefore no natural potential on which to base moral valuation. They speak of the "un-enabled" character of these entities, and claim this deficiency of context justifies their use in scientific research. However, depriving an embryo of its environment does not change its intrinsic nature. To deny the moral standing of the pre-implantation embryo shifts the moral basis away from its intrinsic nature and places it entirely within the realm of external intention, subject to the whim of the research scientist.

Function. Most other arguments relate in some way to the onset of a specific function or capacity. The first and most obvious problem is that the essential functions (and even their minimal criteria and age of onset) are diverse and arbitrarily assigned. Generally they relate to the onset of sentience, awareness of pain, or some apparently unique human cognitive capability such as reflective self-consciousness.

This approach raises a number of disturbing ethical questions. If human moral worth is based on actual manifest functions, then does more of that function give an individual life a higher moral value? And what are we to make of the parallel functional capacities in animals that we routinely sacrifice for food and medical research? Furthermore, what becomes of human moral status with the degeneration or disappearance of such functions? While we might argue that our relational obligations change along with changes in function, such as occur with senile dementia, our society would not sanction a utilitarian calculus and the purely instrumental use of such persons no matter how promising the medical benefits might be.

More fundamentally, from a scientific perspective, there is no meaningful moment when one can definitively designate the biologic origins of a human characteristic such as consciousness. The human being is an inseparable psycho- physical unity. Our thinking is in and through our bodily being, and thus the roots of our consciousness reach deep into our development. The earliest stages of human development serve as the indispensable and enduring foundations for the powers of freedom and self-awareness that reach their fullest expression in the adult form.

From the perspective of this analysis, we can conclude that the embryo has a moral status that is inherent and not an accrued or accumulated quality, and that moral status must begin with the zygote (or clonote). Because it is intrinsic, such moral status, as distinguished from developing relational obligations, is therefore independent of: 1) the means by which the entity came into being (sexual intercourse, IVF, cloning or other);2) the present location of the entity (in- or outside of a natural or artificial womb); and 3) the intention according to which such entity was produced (human reproduction, scientific and medical research, medical therapeutic use, or other).

Failures of fertilization. While inviolable moral standing is attributed to the human embryo, recent scientific evidence suggests that many, perhaps most, early natural initiations in reproduction result in failures of fertilization. If the zygote lacks essential elements such as the necessary complement of chromosomes, proper chromatin configuration and cytoplasmic factors for gene expression, it will also lack an inherent potency, a self-organizing drive in the direction of the mature form. It will not have the characteristics necessary for it to be an organism, and therefore will not be an embryo. Naturally occurring failures of fertilization may still proceed along partial trajectories of organic growth, however. For example, grossly abnormal karyotypes such as trisomies of chromosome number one (the largest chromosome, with the most genes) will form a blastocyst but will not implant (10). Even an egg without a nucleus, when artificially activated has the developmental power to proceed through several cell divisions, yet clearly is not an embryo, or an organism at all. Like a spinning top, the cells contain a certain biologic momentum that propels a partial trajectory of development, but unlike a normal embryo they are unable to bootstrap themselves into becoming an integrated and self-regulating organism.

Some of these aberrant products of fertilization that lack the qualities and characteristics of an organism, appear to be capable of generating ESCs or their functional equivalent (11). Mature teratomas are tumors (generally benign) that generate all three primary embryonic cell types as well as more advanced cells and tissues, including partial limb and organ primordia - and sometimes hair, fingernails and even fully formed teeth. Yet these chaotic, disorganized, and nonfunctional masses are like a bag of jumbled puzzle parts, lacking entirely the structural and dynamic character of organisms. Neither medical science nor the major religious traditions have ever considered these growths to be moral beings worthy of protection, even though they appear to produce ESCs.

\section{SYSTEMS BIOLOGY}

This example of disorganized growth provides a window into an important new conceptual realm in the study of life. 
Through systems biology, we are beginning to recognize how even a small change of one or a few genes can affect the entire downstream working of an enormous network of biochemical processes. Systems biology offers us the view of an organism as a living whole, a dynamic network that is more than the sum of its parts.

The very word organism implies organization, an overarching principle of unity, a cooperative interaction of interdependent parts subordinated to the good of the whole. As a living being, an organism is an integrated, self-developing and self-maintaining unit under the governance of an immanent plan. The philosopher Robert Joyce explains: "Living beings come into existence all at once and then gradually unfold to themselves and to the world what they already but only incipiently are." Joyce continues: "No living being can become anything other than what it already essentially is."(12) For an embryonic organism, this implies an inherent potency, an activated drive toward the mature human form. By its very nature, an embryo is a developing being, its wholeness is defined by both its manifest expression and its latent potential; it is the phase of human life in which the organismal whole produces its organic parts.

Such a conception of the biological organism transcends the 'nothing but its parts' of reductionism. It adds the understanding that a living being is not merely a mechanism but rather, a dynamic system, an interactive web of interdependent processes that expresses emergent properties not apparent in the biochemical parts. Within this dynamic self-sustaining system is the very principle of life, the organizing information and coordinating coherence of a living being. Just as a gyroscope falls when it ceases to spin, so at the moment of death something is lost to the organism. The intangible something that is lost is not the 'vitalistic force' or dualistic 'soul' of certain earlier formulations; rather it is what the new systems perspective adds to the picture-the robust self-regulation that is the defining character of a living being. It is this overarching harmony of the whole, its dynamic balance of being, that distinguishes an organism from the mere physio-chemical material of its parts. This inherent principle of organic unity, in turn, provides the physical identity and continuity (and therefore the moral continuity) of a human being from conception to natural death.

The new perspective of systems biology forms the intellectual grounding for appreciating the physical and moral difference between an embryo and an entity such as a teratoma. A teratoma is an inadequately constituted biochemical system, a partial trajectory of development with an inherent potential for only incomplete and unorganized growth. According to systems biology, the important distinguishing characteristic of an entity having only partial developmental potential is not the visible appearance of its temporary development, however 'normal' it may initially seem; rather it is the lack, at the molecular level, of the structure and organization necessary for an integrated system. With the full complement of coordinated parts, an organismal system subsumes and sustains the parts; it exerts a downward causation that binds and balances the parts into a patterned program of integrated growth and development. Incompletely constituted or separated from the whole, the parts, as subsystems of growth (cells, tissues and organs), may temporarily proceed forward in partial develop ment, but without the self-regulating powers of the organismal system they will ultimately become merely disorganized cellular growth. This distinction could provide the principle for the resolution of our current controversy over ESC research.

If we look back to the $19^{\text {th }}$ and early $20^{\text {th }}$ century and the disputes over vitalism, we may recognize the roots of our current conceptual dilemma. The biochemical description of fermentation established the fact that a cellular function previously assumed to be empowered by a mysteriously immaterial force (and therefore supposedly an inherent indicator of moral-spiritual meaning) could be manifest apart from the living cell. It seemed to follow that all of life is reducible to explanation in terms of physio-chemical description, mere matter and information. This idea increasingly distanced (and eventually disconnected) the moral from the material, relegating all moral reasoning to the realm of culturally constructed social tradition and then, finally, to purely personal belief. Amid the pluralism of opinion, however, such a deracinated and arbitrarily assigned foundation for moral valuation provides no compelling rationale for the authority of moral principle. Most specifically, this concept of the moral allows no naturally grounded, empirically recognizable connection between the intrinsic potency of the developing physical physical form and the moral standing of a living being.

This demotion of the moral, however, was really just an over-extension of the material within the limited terms of our physio-chemical description. Fermentation is not, in fact, the equivalent of life, but a partial and incomplete subsystem of life. Without endorsing forms of substantive vitalism it is important to reaffirm the unique organismal character of living beings. For just as correcting the error of vitalism led to positive progress through the investigation of life on the biochemical level, so, now, to open further avenues of scientific advance, the claims of reductionism need to be supplemented by a richer notion of organismic biology that takes account of embryology and a systems-theoretic perspective.

This conceptual shift is essential for both scientific understanding and advance in establishing the ethical principles that can sustain our scientific exploration. Just as ethical principles can be informed and refined by a fuller scientific understanding of the biological foundations of life, so, likewise, true progress in science need not be divorced from ethical considerations, and in the case of developmental human biology it seems inseparable from it. A proper ethical framework can set the principles that preserve a coherent moral understanding while defining the boundaries of these principles with a clarity and precision that opens avenues of advance for the whole future of developmental biology. Most specifically, by recognizing a distinction between the living whole and the biochemical parts (and partial trajectories of development), we may recognize how small changes in chemical composition can dramatically alter the intrinsic potential and, therefore, the moral meaning of a thing. Just as it was an error to consider chemical processes such as fermentation to be life itself, so also it would be an error to consider a teratoma, (or a similar laboratory construction) to be a living organism. Thus, accord- 
ing to this ethical analysis, there is no fundamental violation of moral principle in producing and using such laboratory constructs for the production of ESCs.

\section{ALTERED NUCLEAR TRANSFER (ANT)}

The foregoing ethical analysis not only explains what is morally troubling about CBR but it also points toward a resolution to our national policy impasse over its use. What CBR produces and then destroys to harvest ESCs is, when fully constituted, a human embryo. According to the perspective presented here, such an entity is an inviolable living being, not a mere laboratory product available for instrumental use. But if the CBR process could be altered so as to produce ESCs from a biologic construct having only partial developmental potential, no embryo would be created or destroyed. Such a proposal, known as altered nuclear transfer (ANT), has been described in a recently released white paper by the President's Council on Bioethics (13). As the author of the ANT proposal (14), I will discuss it in light of the previous ethical analysis as an approach that may lead to a technological solution to our conflict over ESC research.

As discussed above, natural conception signals the activation of the organizing principle for the self-development and self-maintenance of the full human organism. In the language of stem cell biology, this capability is termed totipotency, the capacity to form the complete organism. A naturally fertilized egg, the one cell embryo, is totipotent. In contrast, the term pluripotency designates the capacity to produce all the cell types of the human body but not the coherent and integrated unity of a living being. ESCs are merely pluripotent. This is a difference between the material parts and the living whole.

In standard nuclear transfer, the cell nucleus is removed from a somatic cell and transferred into an oocyte that first has its own nucleus removed. The oocyte then has a full complement of DNA and after it is electrically stimulated, starts to divide like a naturally fertilized egg. This is how Dolly the sheep was produced. ANT uses the technology of nuclear transfer but with a pre-emptive alteration that assures that no embryo is created. The somatic cell nucleus or the enucleated oocyte's contents (or both) are first altered before the somatic cell nucleus is transferred into the egg. The alterations cause the somatic cell DNA to function in such a way that no embryo is generated, but pluripotent stem cells are produced. $\neq$ The laboratory construct that is produced by ANT has only partial developmental potential. It lacks the integrated unity that characterizes a human embryo so the above ethical analysis would permit harvesting its ESCs.

ANT is a broad concept with a range of possible approaches and there may be many ways this technique can be used to accomplish the same end. As described in a January 2006 paper in Nature magazine, stem cell biologist Rudolf Jaenisch

\$ “Because the ANT product lacks essential properties of the fertilized embryo, it is not justified to call it an 'embryo."' Jaenisch, Rudolf. 'Testimony of Rudolf Jaenisch, M.D., Hearing on 'An Alternative Method for Obtaining Embryonic Stem Cells', Committee on Appropriations, Subcommittee of Labor, Health and Human Services, Education', United States Senate Oct. 19, 2005 has established the scientific feasibility of one example of the ANT approach in a series of dramatic experiments in which he procured fully functional ESCs from a construct that is radically different in developmental potential than a human embryo (15). Unfortunately, the news reports have emphasized the inability of the ANT entity Dr. Jaenisch produced to form the placenta. The alteration he used, however, results in a failure of formation that is earlier and far more fundamental than simply an inability to implant in the womb. Due to the alteration, the first division into different cell lineages does not occur, the body axes (top/bottom, front/back) cannot form and the basic human body plan is never established. At this stage a critical deficiency is more rightly considered an insufficiency, not a defect in a being, but an inadequacy at such a fundamental level that it precludes the coordinated coherence and developmental potential that are the defining characteristics of an embryonic organism. In preliminary discussions, a broad range of moral philosophers and religious authorities (including some of the most conservative evangelical and Catholic leaders) have expressed strong encouragement for further exploration of this project.

$\boldsymbol{A N T - O A R}$. Another variation of ANT called oocyte assisted reprogramming (ANT-OAR) has been put forward by Markus Grompe, Director of the Stem Cell Center at Oregon Health Science University. In this variation of ANT, alterations of the nucleus of the adult body cell and the enucleated egg's contents before nuclear transfer would force early expression of genes characteristic of a later and more specialized cell type that is capable of producing pluripotent stem cells. Such a creation, from its very beginning, would never have the actual configuration or potential for development that characterizes a human embryo. As documented on the Ethics and Public Policy Center website this proposal has drawn wide endorsement from leading scientists, moral philosophers and religious authorities (16).

The pre-emptive nature of ANT. The crucial principle of any technical variation of ANT, however, must be the preemptive nature of the intervention. This process does not involve the creation of an embryo that is then altered to transform it into a non-embryonic entity. Rather, the proposed genetic alteration is accomplished $a b$ initio: the laboratory construct is brought into its very existence with a genetic structure insufficient to generate a human embryo. From the beginning and at every point along its development, it cannot be designated a living being. If such a limited biologic construct were accorded a certain cautionary respect-as with all human tissues - this project would not compromise any fundamental moral principles. Moreover, such techniques could be developed using animal models and confidently extended to work with human cells without engaging in research that involves the destruction of human embryos.

The advantages of $A N T$. ANT would provide a uniquely flexible tool for embryonic stem cell research. Embryos left over from IVF procedures represent a limited pool of genotypes. Furthermore, the genomes of these embryos have never proven their capacity to form an organism and, due to mutations, recombinations and re-assortment of alleles in gameto- 
genesis, may carry unrecognized genetic defects. Embryonic stem cells produced by ANT, however, would have genotypes of proven potential. Furthermore, ANT could provide a full range of genotypes, including specific genetic types for tissuecompatible transplantation. In addition, this technique would offer a far wider range of scientific and medical possibilities than ESC lines derived from left over IVF embryos, including generation of diverse and pre-designed ESC lineages for disease modeling and pharmaceutical development. Indeed, in allowing controlled and reproducible experiments, ANT might serve as a temporary bridge to technologies such as direct nuclear reprogramming. Furthermore, in establishing a morally acceptable means for the procurement of ESCs, this important realm of scientific investigation would be opened to federal funding and the advantages of both broad public support and cooperative research collaboration on a national level.

ANT would also unburden ESC research from the additional ethical concerns of the 'left over' IVF embryos, including the attendant clinical and legal complexities in a realm of great personal and social sensitivity. The one remaining link with IVF, the procurement of oocytes, is a subject of intense scientific research and there appear to be several prospects for obtaining eggs without the morally dubious and expensive super-ovulation of female patients.

\section{CONCLUSION}

Throughout the $20^{\text {th }}$ century, the great advances in molecular and cell biology were accomplished largely by studying the biochemical parts apart from their natural place within the whole organism. This approach, which has culminated in the sequencing of the human genome, has now led us back to the study of whole living beings.

As we enter the era of developmental biology, there will be many moral dilemmas; the current conflict over ESCs is just the first of a series of difficult controversies over the experimental use of emerging life that will require that we define with clarity and precision exactly the boundaries we seek to defend. Similar concerns were raised over the past century as we came to understand that human parts such as cell, tissues and organs are not themselves alive in a moral sense. Now, as we deepen our scientific inquiry into developmental biology, we may once again find a way forward by studying parts apart from their place within the living whole. This will be a more difficult challenge, however, both technically and conceptu- ally; our natural intuitions identify the dynamics of developing systems with the moral meaning of living beings.

With the exploration of ANT we open a realm of intellectual dialogue and creative scientific investigation in the search for a solution to our current impasse over the procurement of ESCs. Such a solution must be grounded in deep ethical reflection and careful preliminary studies with animal cells. The incommensurate good of human life, and the corresponding danger of its instrumental use means that the highest levels of caution must prevail as we proceed forward with this project. We must initiate the cooperative dialogue that is essential to frame the moral principles that can at once defend human dignity and promote the fullest prospects for scientific progress and its medical applications. The constructive engagement of science and moral philosophy is a crucial component of this dialogue. The very preservation of our humanity may depend on it.

\section{REFERENCES}

1. Kornberg A 1989 For the Love of Enzymes. Harvard Univ. Press, Cambridge

2. United States Congress 2006 Section 506. In: Labor, HHS, and Education and Related Agencies Appropriations Act, 2006, HR3010. In: H Rept 109-143

3. Weissman I 2005 Stem cell research paths to cancer therapies and regenerative medicine. JAMA 294:1359-1366

4. Hurlbut WB 2002 Personal statement. In: Human Cloning and Human Dignity: An Ethical Inquiry. President's Council on Bioethics, Washington, DC, pp 267-276, http://www.bioethics.gov/reports/cloningreport/appendix.html\#hurlbut

5. Gardner RL 2001 Specification of embryonic axes begins before cleavage in normal mouse development. Development 128:839-847

6. Grabel L, Becker S, Lock L, Maye P, Zanders T 1998 Using EC and ES cell culture to study early development: recent observations on Indian hedgehog and Bmps. Int J Dev Biol 42:917-925

7. Piotrowska K, Zernicka-Goetz M 2001 Role for sperm in spatial patterning of the early mouse embryo. Nature 409:517-521

8. da Costa ALE Abdelmassih S, de Oliveira, FG Abdelmassih V, Abdelmassih R, Nagy ZP, Balmaceda JP 2001 Monozygotic twins and transfer at the blastocyst stage after ICSI. Hum Reprod 16:333-336

9. Wang QT, Piotrowska K, Ciemerych MA, Milenkovic L, Scott MP, Davis RW, Zernicka-Goetz M 2004 A genome-wide study of gene activity reveals developmental signaling pathways in the preimplantation mouse embryo. Dev Cell 6:133-144

10. Boue A, Boue J, Gropp A 1985 Cytogenetics of pregnancy wastage. Adv Hum Genet 4:1-57

11. Byrne JA, Simonsson S, Gurdon JB 2002 From intestine to muscle: nuclear reprogramming through defective cloned embryos. Proc Natl Acad Sci USA 99:6059-6063

12. Joyce RE 1978 Personhood and the conception event. New Scholasticism 52:97-109

13. President's Council on Bioethics 2005 Alternate Sources of Pluripotent Stem Cells: A White Paper. Washington, D.C., http://www.bioethics.gov/reports/white_paper/ index.html

14. Hurlbut WB 2004 Altered Nuclear Transfer as a Morally Acceptable Means for the Procurement of Human Embryonic Stem Cells. President's Council on Bioethics, Washington, D.C.,http://www.bioethics.gov/background/hurlbut.html

15. Meissner A, Jaenisch R 2005 Generation of nuclear transfer-derived pluripotent ES cells from cloned Cdx2-deficient blastocysts. Nature 439:212-221

16. Ethics and Public Policy Center 2005 Production of pluripotent stem cells by oocyte assisted reprogramming. Joint Statement. Washington, D.C. http://www.eppc.org/ publications/pubID.2374/pub_detail.asp ment, but without the self-regulating powers of the organismal system they will ultimately become merely disorganized cellular growth. This distinction could provide the principle for the resolution of our current controversy over ESC research. 